\title{
Side effects of mercury in dental amalgam
}

Titiek Berniyanti and Ninuk Hariyani

Faculty of Dentistry Airlangga University of Dental Public Health Department

Surabaya - Indonesia

\begin{abstract}
Dental amalgam is an alloy composed of mixture of approximately equal parts of elemental liquid mercury and an alloy powder. The popularity of amalgam arises from excellent long term performance, ease of use and low cost. Despite the popularity of dental amalgam as restorative material, there have been concerns regarding the potential adverse health and environmental effects arising from exposure to mercury in amalgam. They have long been believed to be of little significance as contributors to the overall body burden of mercury, because the elemental form of mercury is rapidly consumed in the setting reaction of the restoration. In 1997, 80\% of dentist in Indonesia still using amalgam as an alternative material, and 60\% of them treat the rest of unused amalgam carelessly. In recent years, the possible environmental and health impact caused by certain routines in dental practice has attracted attention among regulators. As part of point source reduction strategies, the discharge of mercury/amalgam-contaminated wastes has been regulated in a number of countries, even though it has been documented that by adopting appropriate mercury hygiene measures, the impact of amalgam use in dentistry is minimal. The purpose of this paper is to examine on studies that relate mercury levels in human to the presence of dental amalgams. It is concluded that even though mercury used in filling is hazardous, if normal occupational recommendations for proper mercury hygiene routines and source of reduction strategies are followed, no occupational health risk can be assumed.
\end{abstract}

Key words: amalgam, mercury, chemical hazard

Correspondence: Titiek Berniyanti, c/o: Departemen Ilmu Kesehatan Gigi Masyarakat, Fakultas Kedokteran Gigi Universitas Airlangga. Jln. Mayjend Prof. Dr. Moestopo no. 47 Surabaya 60132, Indonesia. E-mail: urge01@ rad.nat.id; ninuk hariyani@yahoo.co.id. Telp. 0315018347

\section{INTRODUCTION}

Amalgam fillings typically compose $50 \%$ pure elemental mercury, $35 \%$ silver, $13 \%$ tin, $2 \%$ copper, and a trace of zinc. ${ }^{1,2}$ The metal powders react with liquid mercury to produce an amalgam (or alloy) that provides a flexible material that can be easily packed and shaped., ${ }^{2,3}$ Amalgam fillings are often called silver fillings because of its appearance and composition. ${ }^{2,4}$

The American Dental Association (ADA) prefers the use of amalgam because the fillings are inexpensive and durable, while gold and other composite materials are more expensive and more difficult to fit. Because of its flexibility, the use of amalgam arguably requires less skill. Thus, dentists can usually fill a cavity in less time. Other reasons behind ADA's support of amalgam may include ease of use, low cost, have excellent long-term performance, ${ }^{5}$ additional training and equipment required to use alternative materials ${ }^{3}$ and potential liability associated with acknowledging the dangers of amalgam previously used.

There are many countries, including Indonesia still using amalgam as an alternative material. In 1997, Moetmainah ${ }^{6}$ said that around $80 \%$ of dentist in Indonesia use it. Unfortunately $60 \%$ of them treat the residue carelessness. Despite the ADA recommendation of using amalgam filling, the medical scientific community is now in general agreement, that patient with dental amalgam filling are chronically exposed to mercury. It is clear from the Subcommittee's review that a fraction of the mercury in amalgam is absorbed by the body. People with amalgam have higher concentrations of mercury in various tissues (including blood, urine, kidney, and brain) than those without amalgam. Also, a small proportion of individuals may manifest allergic reactions to these restorations. The average daily absorption of mercury from dental amalgam according to WHO, 1991, around 3 to $17 \mu \mathrm{l}$ per day and that 1.25 to 6.6 times the average mercury absorption from dietary sources. ${ }^{7}$ Mercury is absorbed from many sources, including food and ambient air. Thus, it is not known whether the vast majority of people with amalgam experience has any clinical effect from this small additional body burden of mercury and this is the key question which must be answered in order to resolve the issue of whether amalgam poses a public health risk or not.

Dental technicians and patients should be carefully in using dental amalgam, because of the side effects and do some efforts to minimize it. This article will first examine the history of amalgam fillings. Second, it will review available research to demonstrate the potential health hazards of mercury in amalgam filling, including clinical side-effects and environmental aspects. Third, this paper will discuss some efforts which can do by medical 
technician to minimize the potential health hazards of mercury in amalgam fillings.

\section{The history of amalgam fillings}

Dental amalgam is an alloy composed of a mixture of approximately equal parts of elemental liquid mercury and an alloy powder. ${ }^{5,8}$ The first use of amalgam was recorded in the Chinese literature in the year 659, 5,9 and for the last 150 years, amalgam has been the most popular and effective restorative material used in dentistry. Before the 1970s, amalgam accounted for more than 75 percent of all restorations. ${ }^{5,10}$ During the past 20 years, however, the use of amalgam has been declining, largely due to the decreasing incidence of dental caries, more frequent use of crowns and the availability of tooth-colored alternative restorative materials for certain applications. ${ }^{5}$ However, because of their strengthness, they still use as an alternative restoration until now.

\section{Clinical side effects to dental amalgam}

It has been well-documented and referenced that classic signs of chronic mercury exposure is including gingivitis, alveolar bone loss, loosening and loss of teeth, bruxism, metallic taste, oral ulceration, and excessive salivation. ${ }^{6}$ Besides that, symptoms associated with mercury toxicity can be characterized by tremor, ataxia, personality change, loss of memory, insomnia, anxiety, fatique, depression, headaches, irritability, slowed nerve conduction, weight loss, appetite loss, gastrointestinal problems, and psychological distress. 5,11

Mercury vapor absorption occurs through the lungs, with about $80 \%$ of the inhaled vapor being absorbed by the lungs and rapidly entering the blood circulation, so that mercury can enter and remain in certain tissues for longer periods of time, since the half-life of excretion is prolonged. Two of the primary target organs of concern are the central nervous system and kidneys. There have been three recent autopsy studies relating the presence of dental amalgams in humans to mercury levels in tissue. The studies indicate that mercury vapor exposure from dental amalgams appear to contribute to tissue burdens, especially in the CNS, kidneys, and certain glands. ${ }^{12}$

Mercury also has side effects on oral and periodontal. Trivedi and Talim ${ }^{13}$ showed a histological analysis of gingival tissue adjacent to amalgam restoratives. An inflammatory reaction occurred at $62.5 \%$ of the tissue sites in contact with amalgam, and proliferation of epithelium occurred in $68.7 \%$ of the sites adjacent to amalgam. Turgeon et al. ${ }^{14}$ have a clinical investigation on 30 amalgam Class II fillings that compare with contra lateral sites without amalgam fillings served as controls. They found that clinical procedures involved in restoring posterior teeth with Class II amalgam restorations caused an immediate gingival inflammation characterized by erythema and increased crevicular depth, but without significant migration of the epithelial attachment. After eight months, the experimental areas showed significantly more erythema than did the control areas.

Freden et al. ${ }^{15}$ biopsies gingival tissue adjacent to dental amalgam fillings and control tissue in contact with intact tooth structure. The tissues were analyzed for mercury content by flameless atomic absorption spectrophotometry. All of the biopsies which had been in contact with amalgam fillings showed markedly higher mercury contents than did the control biopsies.

Siblerud $^{16}$ compared oral health parameters of 50 subjects with amalgam fillings with those of 51 subjects without amalgams. Amalgam subjects displayed more gingival bleeding, periodontal disease, metallic taste, and foul breath than did the amalgam-free group. An additional 86 subjects were surveyed before and after amalgam removal. In this group, $86 \%$ of the oral cavity symptoms were either eliminated or improved after amalgam removal.

Study of the relationship between dental amalgam and oral lichen planus showed that some people with oral lichen planus may manifest allergic reactions to these mercury and the removal of their dental amalgam filling showed a total remission of the lesions and considerable improvement. ${ }^{7}$ An epidemiologic case-control study of mercury body burden and idiopathic Parkinson's disease, concluded that the body burden of mercury is strongly associated with Parkinson's disease. ${ }^{17}$

\section{Environmental aspects of dental amalgam}

Since all dental restorative materials are foreign substances, their potential for producing adverse health effects is determined by their relative toxicity and bioavailability, as well as by host susceptibility. Adverse health effects to dental restoratives may be local in the oral cavity or systemic, depending on the ability of released components to enter the body and, if so, on their rate of absorption.

Bindslev, ${ }^{18}$ in his study, said that professional activities performed in dental clinics result in the production of wastes, which can be divided into three major groups i.e. sharps, infectious waste and chemical wastes. In general, the amount of waste generated in dental offices is considered to be relatively small compared with that of other healthcare facilities, such as hospitals, and industry. Hazardous wastes generated by the handling of dental filling materials are generally classified as chemical wastes. Chemical wastes from the dental profession can be sub classified as liquids and solids (Table 1). Among the liquids, mercury contaminated waste water and disposal of photographic solutions are a major environmental concern. Loosening and loss of teeth with amalgam, and trituring surplus during carving and burnishing of amalgam are major environmental concern among the solid. 
Table 1. Categories of liquid and solid waste generated in dental offices ${ }^{18}$

\begin{tabular}{ll}
\hline Solid chemical wasted & Liquid chemical wastes \\
\hline Mercury and amalgam & Mercury and amalgam \\
Contaminated wastes & Contaminated wastewater \\
Lead foils & Photographic solutions \\
Disinfectants & Plating solutions \\
Batteries & Monomers \\
Metals & Solvents \\
Dental materials residues & Disinfectants \\
Drug residues & Oil \\
& Acids/Alkalis \\
& Drug residues \\
\hline
\end{tabular}

There have been periodic concerns regarding the potential adverse health effects arising from exposure to mercury in amalgam. ${ }^{7,5,19-23}$ The industrial discharge of mercury has been reduced markedly in several countries. Subsequently, increased attention has been focused on the uncontrolled discharge of mercury waste from dental clinics.

However, the relative mercury contribution from dental offices to the environmental mercury pollution is not well documented. Mercury consumption for dental purposes was estimated to be 3-4\% world-wide. ${ }^{24}$ National surveys have shown that mercury consumption in dentistry has considerably declined in recent years, largely due to the decreasing incidence of dental caries, more frequent use of crowns and the availability of tooth-colored alternative restorative materials for certain applications. ${ }^{5}$
Figure 1 summarizes the mercury cycle in dentistry. ${ }^{25}$ According to a recent German report, around $46 \%$ of the freshly triturated amalgam will be inserted as new amalgam fillings. Major amalgam particles (around 15\%), surplus in trituration capsules and carved surplus, are expected to be collected for recycling. Minor amalgam particles produced during carving, burnishing, and polishing procedures will be sucked up and transported by the vacuum system. A part of it will sediment in tubes and drains in the clinic. Depending on the presence or absence of an amalgam separating unit in the clinic, a part of the generated amalgam-contaminated sludge will be discharged with the sewage. Lost or extracted teeth with amalgam fillings and amalgam-contaminated waste as trituration capsules and cotton rolls will be discharged with the solid waste and, in most instances, will be subjected to combustion. Corpses with or without amalgam fillings are cremated or buried.

\section{DISCUSSION}

Increasing knowledge about the risk of toxic effects caused by anthropogenic mercury accumulation in ecosystems has resulted in a growing pressure for reduction of the discharge of mercury waste. Consequently, the mercury waste problems of dental clinics have been given increased attention, cause they are also as a source of metal which is toxic in biological groups and difficult to distribute. As we know during handling of dental amalgam as a filling material, the dental staff may be exposed to mercury

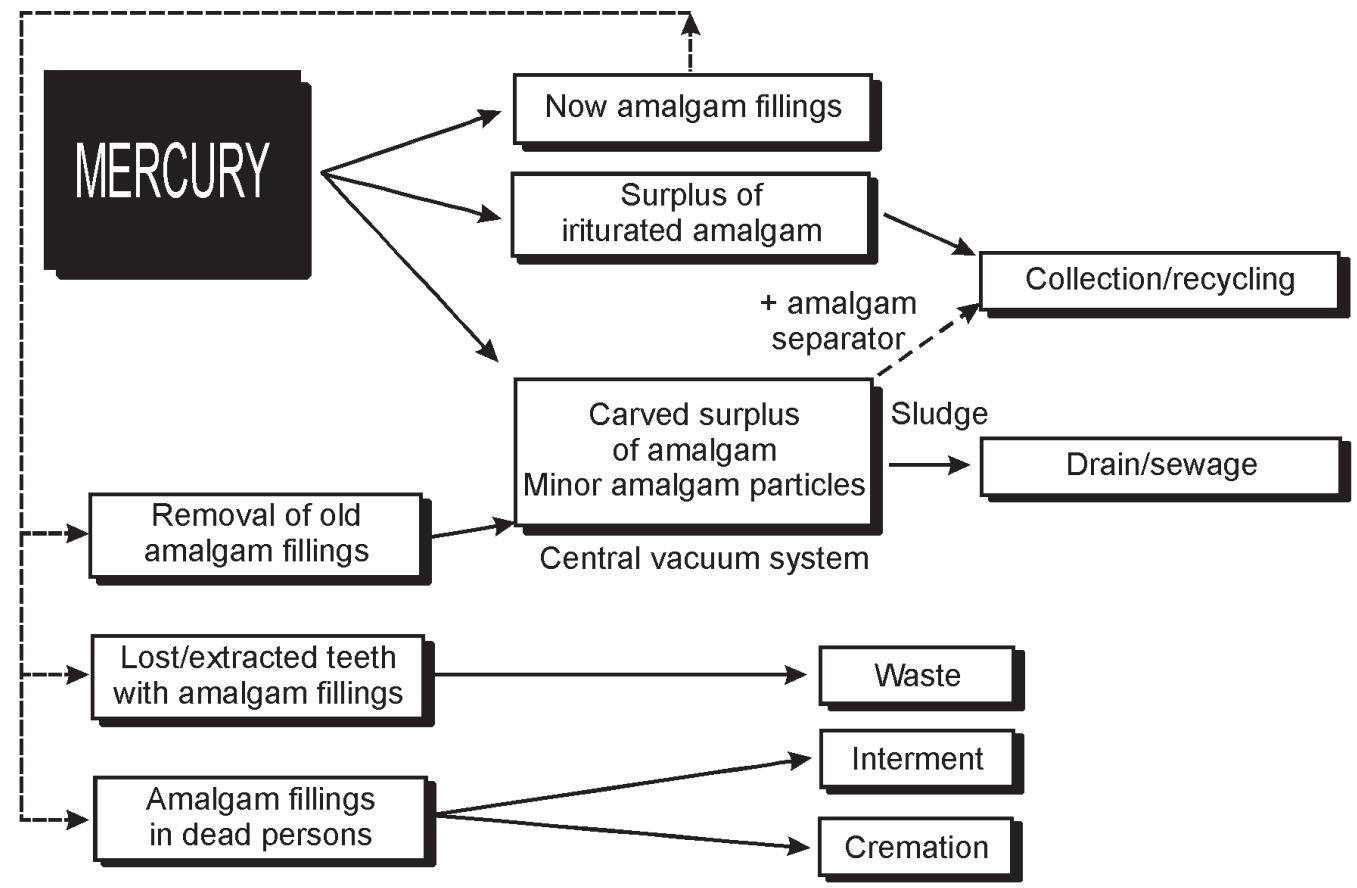

Figure 1. Mercury cycle in dentistry. ${ }^{25}$ 
vapour and the restrictions on handling and discharge of contaminated waste have been established in several countries. Even though, based on the present literature it can be concluded that the concentrations which may occur lie considerably below the internationally recommended limit values for occupational exposure, and far below the limits where toxic effects are described. Water spray cooling and vacuum suction during amalgam removal significantly reduce the evaporation of mercury to levels far below the WHO threshold limit values for both short-term (STEL) and long-term occupational exposure (TLV).

Mercury compound that is really toxic is methylmercury. They are soluble in fat, so that the highest concentration is in the brain. The damage that has happened was permanent, other than that the acut toxic effect of this compound is loss of conciousness to dead. Compared to the general population, dental personnel have shown slightly elevated mercury levels in blood, urine and in certain organs. However, the levels are far below the corresponding limit values, and surveys of dental staff's health status with regard to sensitive parameters such as fertility disorders, do not reveal any increased risk of mercury-related toxic effects. Recently, it has been suggested that sensitive neurobehavioral tests may demonstrate subtle mercuryrelated effects at lower occupational exposure levels than previously observed.

According to the fact above, resin-based dental materials has use as an alternative restoration materials. However, it doesn't mean that material without side effect. Resin-based dental materials and bonding agents contain several known contact allergens or may release allergenic substances (i.e., formaldehyde) by degradation. A recent Danish survey including 2,208 dentists reported that allergic contact eczema caused by (di)methacrylate-containing materials was diagnosed among $0.7 \%$ but estimated by the description of symptoms to be nearly $2 \%$. These results call for attention to the sensitizing potential of certain ingredients in resin-based dental materials and, thus, also for practicing daily routines which avoid direct skin contact with such products.

To ensure proper handling and recycling, the dental team should take care that amalgam scrap is disposed of by companies that adhere to government regulations. As mercury evaporates from amalgam undergoing decomposition by heating, amalgam scrap and extracted teeth with amalgam fillings should not be disposed of in waste undergoing incineration. Amalgam particles in wastewater discharged from dental clinics may theoretically accumulate in wastewater treatment plants. It has been reported that the majority of mercury entering a large modern municipal wastewater treatment plant is removed effectively from the wastewater stream and retained in the sewage sludge. The subsequent handling of the residual sludge may thus result in mercury emissions to the environment. It was recently shown that by incineration of waste water sludge, almost the entire mass of mercury removed from the waste water can be discharged to the atmosphere. Sunlight-mediated emission of elemental mercury from soil amended with municipal sewage sludge has also been demonstrated. Mercury accumulated in waste water treatment plants has caused concern among regulators and resulted in point source reduction strategies that include the dental profession. The relative contribution from dental clinics is, however, scarcely elucidated.

Water spray cooling and vacuum suction during amalgam removal significantly reduce the evaporation of mercury to the levels far below the WHO threshold limit for both short-term and long-term occupational exposure. The efficacy of modern amalgam separators is presently being proven in practice, and it has been shown that the outlet of amalgam particles in sewers can be reduced to at least $10 \%$ of the original mercury level. Major amalgam particles from trituration surplus of those produced during the carving and burnishing of new amalgam restorations are generally collected in coarse filters and sold for refinement. In order to avoid emission of mercury vapor during storage, scrap should be stored in unbreakable containers covered by water or used X-ray solution.

Increasing knowledge of the risk of toxic effects to human and environment from mercury pollution in dental practices should be followed by efforts to minimize it. All hazardous wastes in dental offices must be handled according to national regulation, and the dental team should be adequately educated to collect and handle the mercury wastes. The modern dental team should be well educated to increase the professionallity and public awareness of the biocompatibility aspects of dental materials in all respects. All personnel must aware of the potential sources of mercury vapor in the dental operator. They should work in wellventilated spaces and check the dental operator atmosphere for mercury vapor periodically. Use only precapsulated alloys and an amalgamator with a completely enclosed arm when we need amalgam alloys as an alternative material. All personnel must remove professional clothing before leaving the workplace

If normal occupational recommendations for mercury hygiene routines (e.g., water spray coolant and high vacuum suction during removal of amalgam fillings) are followed, no health risk can be assumed to be associated with occupational handling of amalgam as a dental filling material, except in extremely rare cases of allergy.

\section{REFERENCES}

1. Craig R, O'Brien W, Powers J. Dental materials: Properties and manipulation. 1994. p. 4.

2. Royal MA. Amalgam fillings: Do dental patients have a right to informed consent? Available from http://health.consumercide.com/ dent-infconsent.html. Accessed April 18, 2007.

3. Smith D, Williams D. Biocompatibility of dental materials. Dental Materials. 1982; 3:29.

4. International Academy Oral Medicine and Toxicology. Special Report: when your patients ask about amalgam. J Am Dent Assoc 1990; 120:398. 
5. American Dental Association. Association report: Dental amalgam. Update on safety concerns. J Am Dent Assoc 1998; 129:494-503.

6. Moetmainah. Perhatian dokter gigi terhadap uap merkuri akibat pemrosesan amalgam. Maj Ked Gigi 1997; 30:2.

7. Ziff MF. Documented clinical side effects to dental amalgam. Adv Dent Res 1992; 6:131-4.

8. Phillips RW. Skinner's science of dental materials. $9^{\text {th }}$ ed. Philadelphia: Saunders; 1991. p. 21-30.

9. Li Y, Zhang B, Christen A. Dentistry in China: past and present. Bull Hist Dent 1987; 35:21-8.

10. Rupp NW. Clinical use of some dental materials. Amalgams. J Indiana Dent Assoc 1973; 52(8):432-4.

11. Environmental Protection Agency (EPA), US. Mercury health effects update: Health issue assessment. Washington DC: Office of Health and Environmental Assessment, 1984; PHS publication no. EPA600/8-84-019F.

12. Reinhardt JW. Side-effects: mercury contribution to body burden from dental amalgam. Adv Dent Res 1992; 6:110-13.

13. Trivedi SC, Talim ST. The response of human gingival to restorative materials. J Prosthet Dent 1973; 29:73-80.

14. Turgeon J, Lemay L-P, Cleroux R. Periodontal effects of restoring proximal tooth surfaces with amalgam: a clinical evaluation in children. Can Dent Assoc 1972; 37:255-26.
15. Freden H, Hellden L, Milleding P. Mercury content in gingival tissues adjacent to amalgam fillings. Odontol Revy 1974; 25:207-10.

16. Siblerud RL. The relationship between mercury from dental amalgam and oral cavity health. Ann Dent 1990; 49:6-10.

17. Ngim CH, Devathasan G. Epidemiologic study on the association between body burden mercury level and idiopathic Parkinson's disease. Neuroepidemiology 1989; 8:128-41.

18. Arenholt, Bindslev D. Environmental aspects of dental filling materials. Eur J Oral Sci 1998; 106:713-20.

19. Pinto OF, Huggins HA. Mercury poisoning in America. J Int Acad Prevent Med 1976; 3(2):42-58.

20. Bauer JG, First HA. The toxicity of mercury in dental amalgams. Can Dent Assoc J 1982; 10(6):47-61.

21. Gay DD, Cox RD, Reinhardt JW. Chewing releases mercury from fillings. Lancet 1979; 1:985-6.

22. Langan DC, Fan PL, Hoos AA. The use of mercury in dentistry: a critical review of the recent literature. J Am Dent Assoc 1987; 115:867-80.

23. McHugh WD. Statement: effects and side effects of dental restorative materials. Adv Dent Res 1992; 6:139-44.

24. WHO. Mercury, Environmental health criteria 1. Geneva: World Health Organization, 1976. p. 21-25.

25. Arenholt, Bindslev D. Dental amalgam- Environmental aspects. Adv Dent Res 1992; 6:125-30. 